\title{
APENAS UNA PARTE DE NEGRO Valores socio-raciales y accionar político de las élites de «color quebrado» en Jamaica, Venezuela, y las Antillas Francesas (siglos XVIII y XIX ${ }^{1}$ )
}

\author{
por \\ Alejandro E. Gómez \\ Université Lille 3
}

Este ensayo analiza comparativamente los prejuicios socio-raciales y las aspiraciones igualitarias de las élites de "color quebrado» de Jamaica, Venezuela, y las Antillas Francesas. El objetivo es mostrar cómo esos factores incidieron sobre la actividad política de los miembros de ese sector, sobre todo durante el periodo revolucionario y la era abolicionista. Sostenemos que dicha actividad tuvo consecuencias opuestas, incidiendo tanto sobre la perpetuación como sobre el fin de los regímenes discriminatorios instaurados durante la época colonial.

Palabras Clave: Caribe; raza; revoluciones; igualdad; ciudadanía; mulatos.

Para los criollos, un esfuerzo natural [en contra] del deterioro achacado al color, fue el de descartar cuidadosamente todo indicio que pudiese hacer sospechar que en sus venas circulaba una gota de sangre africana; por este motivo, se vio incluso a cuarterones quejarse en favor del prejuicio. Mientras que en Francia tontos vanidosos deslizaban un de antes de su nombre patronímico, especie de peldaño para adherirse a la casta noble, el desprecio hacia el color africano era considerado, según una expresión de los mismo plantadores, un baluarte colonial; [donde] ser blanco era un honor...

Abate Grégoire, De la noblesse de la peau, 1826.

\footnotetext{
1 Trabajo realizado en el marco del Proyecto del Plan Nacional del MINECO (España) HAR2012-37455-C03-03.
} 
En toda la historia moderna, no hubo otra dicotomía social que tuviera una connotación tan ambigua como la que tuvieron en algunas regiones americanas los individuos libres de origen euro-africano, cuya naturaleza híbrida les ubicó en una suerte de «limbo» estamental e identitario entre los Blancos Criollos y los sectores subalternos de color. La ambigüedad residía principalmente en el hecho de que a pesar de ser libres y de su parcial ascendencia europea, no podían alcanzar los mismos privilegios de que gozaban los Blancos. Ello debido a las rígidas normativas y costumbres de las sociedades coloniales de antiguo régimen, las cuales impedían que pudiesen superar sus tachas de origen (tanto la esclava como la ascendencia ilegítima que muchos tenían), por más claras que fueran sus teces, blanqueados sus linajes, e independientemente de su grado de prosperidad material. Esta negativa de reconocimiento de igualdad estamental se convirtió en un importante factor de tensión durante la Era de las Revoluciones y la llamada Era Abolicionista. Dicha negativa propicio una serie de iniciativas, principalmente por parte de los miembros de las élites de color quebrado, las cuales incidieron de manera determinante sobre la dinámica histórica de las sociedades esclavistas de las que formaban parte, y sobre algunos de los procesos revolucionarios que estallaran en aquella época en el espacio caribeño.

Estos temas fueron primeramente estudiados para el caso de las sociedades de plantación caribeñas (principalmente para el caso de Jamaica) y, luego, para el de las revoluciones franco-antillanas, sobre todo para el caso concreto de las elites cuarteronas de Saint-Domingue ${ }^{2}$. También ha sido abordado en muchos de los trabajos sobre la participación política y la problemática en general de la ciudadanía de los sectores subalternos en las revoluciones hispanoamericanas ${ }^{3}$. La mayoría de los trabajos disponibles, si bien hacen valiosas contribuciones a sus respectivos ámbitos geo-históricos de estudio, no abren sino raramente la escala de análisis fuera de sus respectivos ámbitos culturales, regionales o nacionales. Entre las raras excepciones, tenemos el trabajo colectivo dirigido por los historiadores Greene y Cohen en los años 1970, el cual por primera vez permite tener una visión de conjunto de las problemáticas relativas al conjunto de los libres de color en las Américas, incluyendo las élites de color quebrado ${ }^{4}$. Más recientemente tenemos también el trabajo de Aline Helg sobre el Caribe colombiano, en el cual hace una reflexión transnacional en la que

\footnotetext{
${ }^{2}$ Véase principalmente: Hall, 1972. Sio, 1976. Heuman, 1981. Garrigus, 2006. Rogers, 2009. King, 2011.

3 Hernández, 2001. Helg, 2004. Lasso, 2007. Gómez, 2008. Contreras, 2011.

${ }^{4}$ Cohen y Greene, 1972.
} 
subraya la importancia de la presencia de elites de color, así como la falta de solidaridad de éstas con los esclavos ${ }^{5}$.

En esta última línea de reflexión, el presente ensayo conjuga el estudio de los prejuicios socio-raciales de dichas elites de color con su accionar político en pos de sus derechos de casta de color quebrado. No se trata de un estudio exhaustivo, sino más bien de un esfuerzo de síntesis histórica y de diálogo historiográfico. El principal objetivo es el de exponer la necesidad de profundizar sobre el estudio de la «zonas grises»-para usar la expresión usada por Patrick Bruneteaux ${ }^{6}$ - de las sociedades gran caribeñas, ya que fue en ellas donde se generaron las condiciones de asimilación limitada que permitieron la colaboración entre las élites de color y los Blancos. Esta colaboración fue fundamental pues, por un lado, permitió el surgimiento de sectores intermedios que dieron mayor estabilidad al orden colonial, y por el otro, dio continuidad en el tiempo a los valores socio-raciales y las relaciones de poder del período esclavista.

En cuanto a los territorios a estudiar, se hará principalmente énfasis en las Antillas Francesas (incluyendo a Haití), en Venezuela y en la isla de Jamaica. Estos tres espacios tienen en común haber contado a finales de la modernidad con estructuras societales implantadas de «tres niveles» o «tripartitas» (es decir, conformadas principalmente por Blancos, esclavos y libres de color $)^{7}$, en las que surgieron poblaciones blanco-criollas y se dieron suficientes posibilidades de asimilación como para permitir el surgimiento de élites de «color quebrado». Se trata de espacios en los que (como señalan Vincent Cousseau y Trevor Burnard para los casos de Martinica y Jamaica respectivamente) se produce una sustitución paulatina de la población blanca por la de color, debido precisamente a dichas posibilidades y, más tarde, a las aboliciones de la esclavitud ${ }^{8}$. En los casos de Haití y Venezuela, este proceso fue mucho más violento por las cruentas guerras de independencia que tuvieron lugar en ambos territorios, las cuales diezmaron sus poblaciones blancas 9 .

${ }^{5}$ Helg, 2004: 250-253.

${ }^{6} \mathrm{La}$ expresión es tomada originalmente de Primo Levi, quien en su obra Los hundidos y los salvados (1986) la utiliza para explicar las relaciones entre cautivos y captores, sobre todo las de privilegio, en los campos de concentración nazi. Bruneteaux, $2013 \mathrm{~b}$.

${ }^{7}$ Geggus, 1991: 402. Helg, 1997: 54.

8 Burnard, 2006. Cousseau, 2012.

${ }^{9}$ Wright, 1990: 26ss. Gómez, 2008: 123-124. 
ÉLITES DE COLOR QUEBRADO

La ausencia de restricciones a las manumisiones de esclavos, y a los altos niveles de asimilación que tenían los sectores subalternos en algunas sociedades americanas, permitieron el surgimiento de amplios sectores de libres de color (Libres de couleur, Free Coloreds). Entre estos se encontraban también los individuos de ascendencia híbrida o, como se les llamara en los espacios coloniales hispanos, de "color quebrado» (sang-mêlés para las islas francesas, y mixed-blood para las británicas). Entre estos, los que tenían ascendencia euro-africana eran normalmente denominados como mulatos, el cual, como se sabe, era un término originalmente acuñado en la Península Ibérica en comparación al mulo. Con el pasar del tiempo, las uniones sucesivas entre diversos sectores socio-raciales generaron una amalgama multicolor que, para el caso de los individuos de ascendencia africana, tomó una nomenclatura particular.

En los mundos ibero-americanos se les llamaba «pardos», para referirse a la tonalidad grisácea de su piel, aunque con frecuencia se les incluía también en las llamadas Castas e incluso entre las Plebes. En las Antillas Francesas se hablaba de Gens de couleur y Métis, mientras que en las West Indies británicas se les denominaba Browns, Coloreds, People of Colour y, la denominación legal que los arropaba todos, Mulattoes. Estos sectores estaban a su vez conformados por numerosas subcategorías, las cuales se ordenaban siguiendo una lógica valorativa ascendente en la medida que aumentaban las mezclas con los Blancos. En los mundos hispano-americanos las categorías podían cambiar mucho de región en región, pero normalmente la cadena de uniones raciales comenzaba con los «mulatos», seguía con «tercerón», «cuarterón», «quinterón», y así sucesivamente hasta «Octavón». También existían otras categorías intermedias que definían situaciones particulares, como los «Tente en el aire» (que definía un estancamiento socio-racial) y los «Salto atrás» (que definía un nuevo enlazamiento con Negros).

En el Caribe no hispano, las categorías seguían la misma lógica escalonada ascendente, pudiendo cambiar igualmente de sitio en sitio. En las Antillas Francesas, comenzaban con Sacatra [¿equivalente de salto atrás?], Zarpa (griffe), Mirabou o Mulâtre, y seguían con Quarteron, Métis, y Mamelouc. En las islas británicas en general sucedía algo parecido; allí comenzaba con Mulatto y seguía con Quadroon, Mustee/Mestize, Quinteroon (sólo en Jamaica) y finalmente Octoroon. La semejanza de estas clasificaciones con las hispanas no es coincidencia, ya que como reconocieron en sus obras los plantadores jamaiquinos, Edward Long y Bryan Edwards, las mismas fueron 
inicialmente creadas por los españoles ${ }^{10}$. No obstante, es muy probable que algunas de estas categorías hayan sido ideadas o propuestas por los mismos individuos de color en América, para diferenciarse de otros sectores inferiores subrayando la cercanía de sus linajes con los Blancos. Tal podría ser el caso de «Cuarterón», el cual ya encontramos en El primer nueva crónica y buen gobierno del mestizo Guamán Poma de Ayala escrita en Perú a principios del siglo XVII ${ }^{11}$.

En esta obra se indica que estos individuos ya son prácticamente españoles, con «... sola una oreja tiene de casta negro» ${ }^{12}$. La misma constatación la encontramos más tarde en otros testimonios, tanto en relación a los cuarterones como a los quinterones. Tales son los casos del naturalista germano, Alejandro de Humboldt y de varios viajeros españoles (como Antonio de Ullua y Jorge Juan), quienes constataron en las visitas que respectivamente hicieran a Nueva España y Nueva Granada a fines y a mediados del siglo XVIII, que visualmente cuando se sobrepasaba el grado de quinterón toda sombra de negro había desaparecido ${ }^{13}$. A decir del referido Edwards, en Jamaica algunos pocos individuos de este estrato eran considerados como Blancos $\mathrm{y}$, en consecuencia -como se verá más adelante- tratados como iguales por los mismos Blancos. En el caso de las Antillas Francesas, de acuerdo a la entrada correspondiente a los «Mulâtres» en l'Ecyclopedie escrita por un gobernador de Saint-Domingue, los Blancos estaban dispuestos a aceptar a los Métis una vez que toda tacha de negro hubiese desaparecido, lo que no sucedía sino a nivel de cuarterón ${ }^{14}$.

Debido a las herencias de sus padres blancos, y también por las pocas, aunque a veces jugosas oportunidades de hacer dinero (sobre todo en el área del comercio o las artes manuales), muchos miembros de las elites de color se convirtieron en propietarios, alcanzando algunos un elevado nivel de prosperidad material ${ }^{15}$. En Venezuela, para mediados del siglo XVIII, algunos pardos tenían haciendas de proporciones medias, sobre todo en los Llanos, en las que poseían numerosos esclavos. También poseían un gran número de casas en las ciudades, las cuales en su mayoría tenían alquiladas como tiendas. Sólo a manera de ejemplo, mencionemos el caso de Diego Ignacio Mejías Landaeta, que debió ser uno de los pardos más ricos de Caracas, quien para

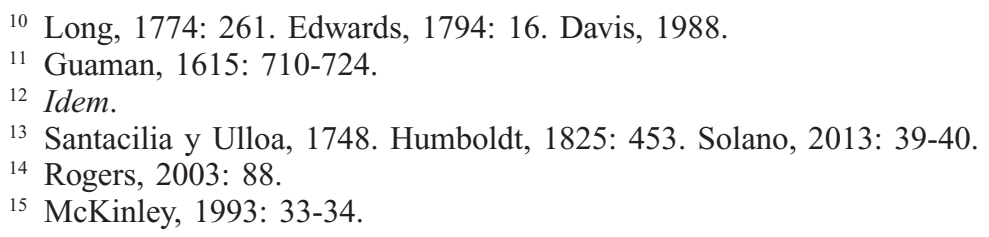


1807, según su testamento, poseía 26 casas, administraba un caudal familiar de 8800 pesos, y distintas personas le adeudaban otros 900. Otros incluso tenían dinero suficiente como para celebrar ostentosas fiestas, hacer jugosas donaciones caritativas y hasta donar un sagrario de plata que costó 5000 pesos a la iglesia de Altagracia, que era el templo de los pardos. Muchos pardos también se vanagloriaban por tener alguna educación $\mathrm{y}$, por lo general en toda la América Española, pensaban que habían mejorado su «estimación» por haber servido fielmente al rey en las milicias ${ }^{16}$.

En el caso de Jamaica, para mediados del siglo XVIII muchos Coloreds poseían terrenos más allá de las fronteras de las grandes plantaciones de los Blancos por un valor de $300.000 £$. Con el pasar del tiempo, estos se convirtieron en prósperas plantaciones. Para el primer tercio del siglo siguiente, eran además dueños de grandes cultivos de pimiento, café y muchas casas en las ciudades. En esa misma época, 400 (2\%) de los alrededor de 30.000 individuos libres de color que habitaban la isla eran calificados como ricos. Algunos de estos habían sido educados en Europa, por lo que se decía que eran más ilustrados que muchos plantadores blancos. Para 1830, se estima que el conjunto de libres de color era dueño del $22 \%$ de los esclavos de la isla, es decir, de unos $70.000^{17}$. Los más prósperos, como en los casos de los cuarterones James Swaby, Thomas Drummond (quienes poseían grandes plantaciones con numerosos esclavos) y del mulato Daniel Saa (quien era dueño de imponentes casas en Spanish Town), eran incluso aceptados socialmente por los Blancos. Estos raros ejemplos de aceptación, como bien subraya Gad Heuman, no significaban una mejora de las relaciones entre el conjunto de Blancos y los Coloreds de la isla. No obstante, cuando comparamos esta situación con otras sociedades esclavistas anglo-sajonas, la misma es muestra de la excepcionalidad de la sociedad jamaiquina ${ }^{18}$.

Estos patrones de prosperidad se repetían aun con más fuerza en las Antillas francesas, donde para mediados del siglo XVIII muchos Gens de couleur habían amasado grandes fortunas. Esto se notaba en las ciudades más importantes, donde poseían una parte importante de las propiedades urbanas: en la ciudad sureña de Les Cayes el $15 \%$ de los inmuebles pertenecían a mulatos, mientras que en la ciudad martiniquesa de Saint-Pierre las familias de color eran propietarias de un gran número de casas. También se dio el caso que se convirtieran en grandes terratenientes como sucediera en SaintDomingue, hasta el punto de conformar lo que John Garrigus denomina como

\footnotetext{
${ }^{16}$ Pellicer, 1996: 119n; 2005: 61ss.

17 Hall, 1972: 194. Heuman, 1981: 84.

${ }_{18}$ Hall, 1972: 200-201. Heuman, 1981: 10-84.
} 
una «clase de plantadores libres de color» ${ }^{19}$. Allí los cuarterones llegaron a tener propiedades de más de 300 esclavos, y un patrimonio que equivalía al de los Grands Blancs medios. Según Raimond, para 1789 los individuos de su condición poseían un tercio de las tierras, y la cuarta parte de los esclavos de la colonia. Él mismo contrajo segundas nupcias con una mulata que aportó una dote de 177 mil libras, e incluso una señoría en al suroeste de Francia. Como pasaba en Jamaica, hubo casos en que se confundían con Blancos de la elite, como fue el caso de la rica familia franco-dominicana Trichet, cuyos miembros además usaban los títulos de Sieur y Madame ${ }^{20}$.

\section{DisCRIMINACIÓN DE LOS BLANCOS}

A pesar de todo el legado material e inmaterial que gozaban las elites de color quebrado, la tacha de la esclavitud era un rasgo que marcaba negativa y permanentemente sus linajes. Algo similar podría decirse de la ascendencia «bastarda», lo cual, en las sociedades estamentales de antiguo régimen, era también signo de envilecimiento, más allá del estatuto socio-racial que se tuviera. Ambas variables tuvieron una incidencia en extremo negativa sobre la «estimación» que tenían los individuos de color. Esto se puede ver claramente en una carta que enviaran los miembros del Cabildo de Caracas al rey de España en 1796:

Los pardos o mulatos son vistos aquí con sumo desprecio, y son tenidos y reputados en la clase de gente vil (...) Ellos han de descender precisamente de esclavos, [y] de hijos ilegítimos, porque los que se llaman mulatos, o pardos son los que traen su origen de la unión de blancos con negras ${ }^{21}$.

En Saint-Domingue, según indicara un noble francés que viviera en esa colonia, todo descendiente de Negros al menos hasta la sexta generación sufría un gran desprecio social. Incluso cuando un blanco desposaba una mulata, a partir de ese momento era considerado como una persona «malcasada» (mésalliée) y «despreciable» ${ }^{22}$. En cuanto a la bastardía de origen de los Gens de couleur, al igual que sucediera en la América Española, la noción se racializó para consolidar la nobleza de las élites blanco-criollas. El lobby de los plantadores en París, con frecuencia resaltó su origen ilegítimo, mientras que los defensores de los Negros Libres llegaron incluso a tildarles de «es-

\footnotetext{
${ }^{19}$ Garrigus, 2006: 177.

${ }^{20}$ Bénot, 1988: 60-61. Rogers, 2003: 90-91. Garrigus, 2006. King, 2011: 81ss.

${ }^{21}$ Cf. Cortés, 1978: 33.

22 D'Auberteuil, 1777: 73, 79.
} 
pecie bastardizada» ${ }^{23}$. En el caso de Jamaica, el problema del origen bastardo tenía un carácter más jurídico, debido a que solamente los hijos legítimos de colonos tenían derecho a convertirse en súbditos británicos. De aquí que en 1782, el presidente de la asamblea de la isla, Richard Barrett, expresara, ante las demandas de los libres de color, que estos no habían sido despojados de nada, pues simplemente no descendían de súbditos británicos (children of the people). Ello no quitaba prejuicios subyacentes mucho más viscerales, como indicara en otra ocasión el mismo Barrett:

Desde pequeños estamos acostumbrados a mantener a los mulatos a distancia. (...) más apreciamos la sangre pura de un campesino británico que el torrente que fluye en las venas de los otros descendientes de negros ${ }^{24}$.

Todos estos testimonios pertenecen a finales del siglo XVIII, momento en que el desprecio hacia los afro-descendientes de color de condición libre llegó a su punto más elevado. Esto se debió a diversas razones, pero sobre todo al aumento del número de individuos de esa condición, a las crecientes aspiraciones socio-políticas de las elites de color quebrado, y también al impacto de lo que podríamos denominar como tipologismo de las luces. Por regla general, las legislaciones discriminatorias que se aplicaron en las distintas regiones culturales se parecían mucho entre sí, pero, como es lógico, no coincidían en su concepción ni en su aplicación desde un punto de vista cronológico. En los mundos hispanos, la legislación socio-racial estuvo desde tiempos de la Conquista marcada por los principios estamentarios y las relaciones de intolerancia a la alteridad existentes en la Península Ibérica, aunque adaptadas a las incipientes realidades del Nuevo Mundo ${ }^{25}$.

En el caso concreto de los pardos, las primeras medidas discriminatorias surgen cuando su número aumenta en lugares como Venezuela a principios del siglo XVII. Este hecho hace que rápidamente se les prohíba ocupar cargos públicos (1621), se les impida ascender por encima del grado de capitán en las milicias (1649), lo que fue seguido por un sinnúmero de medidas que les segregó cada vez más ${ }^{26}$. Los libres de color, en tanto que miembros de las

${ }^{23}$ Gerber, 2013: 574-575, 587.

${ }^{24}$ Cf. Hall, 1972: 211.

25 En la América Española - como indica Jean-Paul Zuñiga- a diferencia de Castilla, los mecanismos legales discriminatorios no buscaron excluir a los considerados como inferiores (ya asimilados en las sociedades coloniales), sino más bien justificar la lógica racial de las jerarquías socio-estamentales emergentes; lo cual podría explicar, al menos en parte, los elevados niveles de asimilación que tuvieron las colonias españolas y otras similares en el Nuevo Mundo. Zuñiga, 1999: 450.

${ }^{26}$ Langue, 1997. 
Castas, también estaban sujetos al pago de las tributaciones correspondientes a los individuos de esta condición. De aquí que desde el siglo XVII, en diversos territorios comenzaran a elevar solicitudes a la Corona para que se les exonerara de tales gravámenes aludiendo su pretendida calidad superior ${ }^{27}$.

En otros espacios culturales caribeños el proceso fue más precipitado. En Jamaica, a los libres de color -al igual que sucedía, dicho sea de paso, con los miembros de la pequeña comunidad de judíos sefardíes- se les prohibía presentarse como candidatos para la asamblea local, pero tenían derecho al voto; esto se les prohibió expresamente en 1733. Poco antes, en 1711 y 1713, se les había vedado respectivamente ocupar cargos públicos y que pudiesen ser supervisores en las plantaciones. Hacia mediados de siglo, la devastadora revuelta de esclavos Coromanti y el creciente aumento de Coloreds propietarios hizo que, en 1761, se prohibiera a cualquier blanco dejar en herencia más de $1200 £$ (libra jamaiquina, que era igual a tres quintos de la metropolitana) a cualquier negro o persona de color, e incluso comprar cualquier propiedad por encima de $2000 £^{28}$.

En las Antillas Francesas se produjo un agravamiento similar de las medidas discriminatorias, pero, a diferencia de los espacios hispano y británico, éste tuvo lugar en forma precipitada en el último tercio del siglo XVIII. Hasta ese momento, todos los libres de color habían gozado de plena igualdad con los Blancos, como establecía el Código Negro de 1685. La situación cambió debido al crecimiento demográfico de los libres de color resultante de las numerosas emancipaciones de esclavos que siguieron a las guerras de la época, a la llegada de inmigrantes metropolitanos de pocos recursos que competían en diversos ámbitos con aquellos, y al temor surgido tras la revuelta de negros liderada por Makandal en Saint-Domingue de 1757. A este mismo contexto pertenecen el alza de los impuestos que pechaban las emancipaciones de esclavos, el establecimiento de libros de bautismo distintos para Blancos y libres de color (una práctica que, dicho sea de paso, era común en la América Española), y el aumento de la misoginia contra los Gens de couleur a manera de excluirlos de la sociedad «decente» de los Blancos. El deterioro de la imagen racial de los afro-descendientes de color en el conjunto de las islas francesas disminuyó el número de matrimonios mixtos, pero no detuvo los matrimonios con Blancos; sobre todo entre miembros femeninos de las elites de color quebrado con inmigrantes de origen humilde ${ }^{29}$.

\footnotetext{
27 Contreras, 2006: 98. Solano, 2013: 44.

28 Hall, 1972: 197.

29 Garrigus, 1996. Rogers, 2003. Elisabeth, 2003. Regent, 2012. Cousseau, 2012.
} 
AlgunAS NORMATIVAS DISCRIMINATORIAS QUE PESABAN SOBRE LOS LIBRES DE COLOR PARA FINES DEL SIGLO XVIII

\begin{tabular}{|c|c|c|}
\hline Antillas Francesas & Venezuela & Jamaica \\
\hline $\begin{array}{l}\text { - Salir después de las } 9 \text { de } \\
\text { la noche } \\
\text { - Usar los mismos tejidos } \\
\text { que los Blancos } \\
\text { - Usar el tratamiento sieur } \\
\text { - Ejercer ciertos oficios, } \\
\text { como la orfebrería, la } \\
\text { medicina y la cirugía. } \\
\text { - Portar armas } \\
\text { - Acceder a empleos públicos } \\
\text { - Tener los mismos puestos } \\
\text { que los Blancos en las } \\
\text { iglesias } \\
\text { - Restricciones para } \\
\text { matrimonios mixtos } \\
\text { - Tener grados de oficiales en } \\
\text { las milicias } \\
\text { - Comer con los Blancos } \\
\text { - Ilegalización de apellidos }\end{array}$ & $\begin{array}{l}\text { - Salir por las calles por la } \\
\text { noche } \\
\text { - Usar prendas lujosas y } \\
\text { alfombras en iglesias } \\
\text { - Uso del tratamiento de don } \\
\text { - Tener acceso a los colegios } \\
\text { y universidades } \\
\text { - Llevar armas } \\
\text { - Ocupar cargos públicos } \\
\text { - Gozar de un grado mayor a } \\
\text { capitán en las milicias } \\
\text { - Asistir a las mismas iglesias } \\
\text { que los Blancos } \\
\text { - Ley para impedir } \\
\text { matrimonios desiguales } \\
\text { - Caminar junto a Blancos } \\
\text { en las calles, o que se les } \\
\text { permitiese el acceso a sus } \\
\text { casas } \\
\text { - Uso de apellidos europeos }\end{array}$ & $\begin{array}{l}\text { - No pueden ocupar } \\
\text { cargos públicos } \\
\text { - No pueden ser } \\
\text { mayorales en } \\
\text { plantaciones } \\
\text { - Emplear Blancos, } \\
\text { o impuesto de } \\
\text { deficiencia } \\
\text { - No pueden votar } \\
\text { - Rendir testimonio en } \\
\text { cortes contra otros } \\
\text { libres de color y } \\
\text { contra Blancos } \\
\text { - Limites en herencias } \\
\text { de padres blancos }\end{array}$ \\
\hline
\end{tabular}

Existieron también mecanismos legales que permitieron a las elites de los afro-descendientes de condición libre mejorar su estatus. En Jamaica, desde principios del siglo XVIII fueron introducidas las llamadas Actas de Privilegio (Acts of Privilege). Este mecanismo, único para la época en el ámbito colonial americano, fue introducido en 1707, pero no fue sino hasta 1733 que su uso se generalizó. El mismo consistía en un reconocimiento adoptado por la Asamblea Legislativa (House of Assembly) de la isla, que permitía a los beneficiados gozar de mayores privilegios. Las actas en cuestión no constituían una legitimación de derechos perdidos, sino más bien gracias extraordinarias que se concedían a individuos meritorios que no tenían derechos a ser ingleses debido a su origen bastardo. Únicamente los libres de color más adinerados 
podía hacer tales peticiones, debido a lo mucho que costaba el proceso: $90 £$ sólo para formalizar la petición. Como alegatos, los peticionarios daban datos sobre su entorno familiar, en particular sus ancestros blancos (incluyendo amantes), prueba de practicar la fe cristiana, de independencia económica, y de un elevado nivel de educación en la metrópoli si fuere el caso. He aquí un ejemplo de 1782:

Que el peticionario hizo que todos sus hijos naturales sean bautizados, educados e instruidos en los principios de la religión Cristiana, y pretende criarlos en forma cortés, y conferirles suficiente fortuna a manera de elevarlos por encima del nivel común de la gente de color (...) Debido a las desafortunadas circunstancias de su nacimiento, están sujetos y son expuestos a las mismas normativas de gobierno, y a las mismas penas y penalidades, como si fueran negros libres y mulatos, quienes no tienen educación. Por lo tanto, el peticionario humildemente ruega, que la Casa [de la Asamblea] tenga la bondad de permitir de proponer una moción, para que se otorgue (...) a los mencionados niños los mismos privilegios que hasta ahora han sido concedidos a personas bajo las mismas circunstancias ${ }^{30}$.

Durante el último tercio del siglo XVIII, la mayor parte de los peticionarios fueron individuos de color quebrado: Mustees (90), Quadroons (245), Mulattoes (176), y sólo hubo un caso de un Negro Libre. Muchas veces se trataba de mujeres de color que solicitaban privilegios en beneficio de sus hijos. En total, hasta su suspensión en 1802 (probablemente debido a temores asociados a la Revolución Haitiana), se hicieron unas 512 peticiones de las cuales fueron aprobadas sólo 128. Las concedidas tenían deferentes grados de privilegios, resultando sólo 4 individuos beneficiados con plenos derechos en términos de sufragio y capacidad para ocupar cargos públicos. El mecanismo se reinstauró en 1823, debido principalmente a las demandas de las elites de color y a los intereses asambleístas blancos en no colectivizar sus reivindicaciones, siendo concedidas 200 más en forma individual ${ }^{31}$.

En las últimas décadas del siglo XVIII, los pardos más acomodados y blanqueados de la América Española también procuraron valerse del sistema de gracias existente desde hacía tres siglos en los Mundos Hispanos. El mismo lo usaron para ser dispensados de ciertos «defectos» (como la ilegitimidad y el origen «servil» de los linajes) para poder realizar ciertas ocupaciones y, luego, para que se les reconociese como Blancos. Esto lo pretendieron lograr elevando peticiones ante la Cámara del Consejo de Indias, que era la entidad metropolitana encargada de otorgar gracias reales a los habitantes de América.

\footnotetext{
30 Cf. Hall, 1972: 199.

31 Ibidem: 201. Sio, 1976: 8-10. Heuman, 1981: 6.
} 
En 1795, esta entidad decidió incorporar un oneroso arancel para la concesión de tales gracias a través de la conocida Real Cédula de Gracias al Sacar. Se trataba de un mecanismo legal que había sido inicialmente aplicado en España en 1773, y mediante el cual, en la versión extendida a las Indias, tras el pago de dicho arancel un individuo podía ser dispensado de su calidad de pardo (500 reales) o de quinterón (800 reales). Para ello previamente debían haber demostrado que gozaban de los méritos necesarios, en forma parecida a como lo hacían sus contrapartes jamaiquinos ${ }^{32}$.

En total, entre 1760 y 1808 , se hicieron 40 peticiones de blanqueamiento por parte de pardos americanos, siendo casi la mitad de Venezuela; un número sustancialmente inferior que en Jamaica, lo que pudo deberse, como sostiene Ann Twinam, al desconocimiento de las leyes por parte de las poblaciones de color americanas, con excepción de los pardos venezolanos. Hasta 1795, sólo fueron concedidas dispensas con fines ocupacionales $y$, una vez introducido el arancel, fueron concedidas gracias más amplias en términos de igualdad con los Blancos ${ }^{33}$. Para el caso venezolano, esas «gracias» no fueron de mucha ayuda para quienes las adquirieron, pues ningún pardo dispensado pudo mejorar realmente su condición socio-racial. Prueba de ello son los múltiples reclamos elevados al rey, para que se acataran los fallos ${ }^{34}$.

Por línea general, las élites de color quebrado siempre mantuvieron una postura humilde ante los Blancos y, sobre todo, conciencia de que pertenecían a una clase inferior. Para el caso de Venezuela, esto se puede apreciar en los numerosos casos de disensos matrimoniales ${ }^{35}$, y en sus solicitudes de dispensa de calidad. En relación a Jamaica, a decir de Edwards, los mulatos son «humildes, sumisos, modestos» en su comportamiento con los Blancos, como si «sus ánimos parecieran hundirse bajo la conciencia de [inferior] condición $\gg{ }^{36}$. En las Antillas Francesas no existieron dispensas ni privilegios especiales, pues los libres de color gozaban de los mismos derechos que los colonos blancos desde fines del siglo XVII. De aquí que su actitud haya sido - como sugiere John Garrigus ${ }^{37}$ - francamente sagaz a la hora de intentar revertir la insidiosa discriminación de la que fueron objeto desde el último tercio del siglo XVIII.

\footnotetext{
Twinam, 2015.

Idem.

${ }^{34}$ Cortés, 1978: 49, 197, 210.

35 Pellicer, 2005: 61ss.

${ }^{36}$ Edwards, 1794: 21.

${ }^{37}$ Garrigus, 1996: 28.
} 
Esto se pudo apreciar en las iniciativas políticas emprendidas por los delegados que llegaron a Francia a fines de la década de 1780. En un principio actuaron ante la Corte, llegando incluso a obsequiar una embarcación al rey. Luego, una vez que estalla la revolución en la metrópoli, buscaron lograr apoyos para hacerse merecedores de la ciudadanía. Para lograr este objetivo, Julien Raimond hizo uso de muchos de los argumentos evocados previamente o en la misma época por sus equivalentes jamaiquinos y venezolanos: que muchos eran letrados pues habían sido educados en Francia, que habían llegado al nivel más alto de mezcla con blancos, que eran propietarios amos de esclavos, que habían probado su fidelidad en las milicias, y que eran hijos legítimos. Raimond alegaba además que «eran originalmente el fruto» del amor entre un blanco y una negra. "Acaso no somos propietarios, contribuyentes de impuestos, y sobre todo, de gran utilidad», reclamó en uno de sus escritos cuando no se les tomó explícitamente en cuenta como electores para las nuevas asambleas coloniales creadas por la Asamblea Nacional en 1790. Más de dos décadas más tarde, cuando las Cortes de Cádiz excluyeron de la ciudadanía a los descendientes de África, los «españoles pardos» de Lima hicieron reclamos en casi los mismos términos; alegando, además, que eran más «honrados, virtuosos e instruidos» que los indios e, incluso, que las plebes europeas ${ }^{38}$.

\section{Prejuicios de LAS Élites De COLOR}

Entender la naturaleza de todas estas alegaciones, pasa por entender los valores socio-raciales de las sociedades en que tuvieron lugar y, más concretamente, sobre la forma cómo estos valores eran compartidos y reinterpretados en beneficio propio por las élites de color quebrado. A fines del siglo XVIII, viajeros como el referido Humboldt y el renano Alexandre-Stanislas de Wimpffen a su paso por la Nueva España y por Saint-Domingue respectivamente, se dieron cuenta de la importancia social que tenía le cercanía de la ascendencia blanca europea y la lejanía de la negra esclava. El primero equiparó esa valoración con la lejanía de moros y judíos y la cercanía con cristianos que existiera en España, y el segundo subrayó cómo los cambios en las tonalidades hacia el blanco «...genera distinciones de rango, de mérito, de nacimiento, de honores, incluso de fortuna ${ }^{39}$.

\footnotetext{
${ }^{38}$ Españoles Pardos, 1812.

39 Humboldt, 1811: 51. Wimpffen, 1993: 76-77.
} 
Por su parte, Edward Long en su Historia de Jamaica, escribió que en las colonias españolas era «más ventajoso mezclar la descendencia en ascendente o cada vez más blanca», hasta el punto que «los cuarterones no aceptan estar en compañía de mulatos». Según Long, esta situación sólo se diferenciaba de la situación en Jamaica, en que en esta isla no se establecen diferencias entre los tercerones y los cuarterones ${ }^{40}$. Por otro lado, como observara un escritor británico que pasara por Jamaica a mediados del siglo XIX, los que llama como «cuarterones blancos» llegaban a denegar su ascendencia africana, lo que era imposible ya que algún rasgo físico o su conocida historia familiar siempre delataba su origen ${ }^{41}$.

Los reclamos y alegatos por parte de miembros de las élites de color quebrado no buscaban simplemente revertir una legislación que les era adversa. Los mismos reflejaban una convicción mucho más profunda, según la cual, debido a los progresos materiales e inmateriales que ellos pensaban haber alcanzado, se habían deslastrado de su origen doblemente envilecido lo que les hacía meritorios de poseer el estatus de Blancos. Esta convicción se reflejaba en distintos ámbitos, como la práctica de estrategias maritales que buscaban preservar la «calidad» de sus linajes (similar, dicho sea de paso, a las practicadas por los Blancos Criollos), la forma peyorativa cómo trataban a otros sectores libres de color considerados por ellos como inferiores, y en sus posturas favorables al régimen esclavista. Sobre esto volveré más adelante.

Estas actitudes prejuiciosas de las élites de color quebrado fueron criticadas por algunos abolicionistas y políticos liberales, aunque estos les exoneraron de la responsabilidad. En Francia, el Abate Grégoire acusó a los Blancos «...de suscitar la aversión entre los negros y los sang-mêlés» ${ }^{42}$. Algo similar opinaba el revolucionario neo-granadino, Pedro Fermín de Vargas, aunque en un sentido más amplio y achacando dichas actitudes (incluyendo la necesidad que tenían los mulatos de ocultar su origen africano), a las políticas imperiales de España para mantener divididos a los hispano-americanos ${ }^{43}$.

\section{Hacia los esclavos y otros libres de color}

Hasta 1789, al parecer nadie en Francia se había preocupado por la causa de los derechos de los Gens de couleur; ni siquiera los miembros de la

\footnotetext{
${ }^{40}$ Long, 1774: 261.

${ }^{41}$ Trollope, 1860: 81 .

42 Grégoire, c1996: 41.

${ }^{43}$ Miranda, 1938: 250-251.
} 
Sociedad de Amigos de los Negros, quienes, para ese entonces estaban más preocupados por poner fin a la trata de esclavos. Los delegados cuarterones de Saint-Domingue tampoco hicieron mucho esfuerzo por llamar su atención, pues una vez en la metrópoli, a quienes contactaron fue al lobby de los plantadores reunidos en el llamado Club Massiac. A estos dirigió una moción uno de dichos delegados, Vincent Ogé, en la cual tocaba varios temas de pretendido interés mutuo resaltando el cuidado que había de tener con el principio de libertad y los negros esclavos. En tal sentido, sugería que había que tomar las medidas necesarias para evitar que los esclavos se rebelasen, y luego acabaran con sus propiedades y familias ${ }^{44}$. En una tónica parecida, Raimond expresaba en otro escrito su voluntad porque los individuos de su condición y los Blancos constituyesen «una sola clase con todos los hombres libres». En el mismo, este delegado manifestaba igualmente su convicción de que se podía seguir conviviendo con esclavos, hasta tanto no se encontrase «...un método seguro para llevarlos a un estado de libertad» ${ }^{45}$.

Las gestiones que realizaban las elites cuarteronas en la metrópoli para lograr derechos únicamente para los individuos de su condición, fue considerada como un «atrevimiento» para los esclavos. Esto se puede apreciar en un cuaderno de dolencias escrito por un supuesto esclavo de Martinica en 1789:

Acabamos de enterarnos con extrema decepción que los mulatos lejos de interesarse por su madre, hermanos, hermanas esclavas, han osado mostrarnos como indignos de disfrutar como ellos de las bondades que otorgan las paz y la libertad (...) No es para nada la envidia lo que nos obliga a quejarnos de los mulatos, sino el atrevimiento que ellos han tenido al hacer un plan de libertad sólo para ellos a pesar de que todos pertenecemos a una misma familia ${ }^{46}$.

A fines de 1789, luego que el lobby de los plantadores ignoraran las propuestas de los delegados cuarterones, Raimond les acusó de haber «...confundido artificiosamente la causa de las gentes de color con la de los esclavos... $»^{47}$. Fue sólo entonces cuando se produjo un acercamiento con la Sociedad de Amigos de los Negros, cuyos miembros, ante la imposibilidad de acabar con la esclavitud y la trata de esclavos, concentraron sus energías en poner fin a la discriminación de que eran víctimas los Gens de couleur. La negación de los Blancos a reconocer a estos el estatus de ciudadano aprovechando una ambigüedad jurídica en la ley de creación de asambleas coloniales de abril de

\footnotetext{
44 La Révolution française et l'abolition de l'esclavage.

45 Cf. Cook, 1941: 142.

46 Cf. Pouliquen, 1989: 73.

47 Raimond, 1791.
} 
1790, hará que estalle una verdadera guerra civil en Martinica y una gran sublevación en Saint-Domingue dirigida por el referido Ogé. Más tarde, en 1792, la Asamblea Legislativa metropolitana dará curso a las aspiraciones de las elites de color quebrado al permitir el acceso a la ciudadanía sólo a aquellos libres de color con bienes de fortuna y que fuesen hijos legítimos ${ }^{48}$. Este decreto animó a un grupo de Coloreds jamaiquinos a hacer una petición ante la Asamblea Legislativa de la isla en diciembre de ese mismo año. En la misma pedían que se les devolviese el estatus de súbditos británicos con plenos derechos. La iniciativa fracasó ante las delaciones de los asambleístas blancos y porque, en el ínterin, falleció su principal artífice: un cuarterón de nombre Dickson ${ }^{49}$.

Más de una década más tarde, entre 1810 y 1811, durante la Revolución de Caracas, los pardos de la élite defendieron en escritos de prensa al gobierno autónomo que había instaurado una ciudadanía censitaria que dejaba fuera de los procesos electorales a los sectores más bajos de los libres de color ${ }^{50}$. Poco más tarde, en 1812, los llamados a sí mismos «pardos españoles» de la ciudad de Lima criticaron con encono su exclusión de la ciudadanía por parte de las Cortes de Cádiz, aludiendo que no tenían la culpa de ser descendientes de esclavos ${ }^{51}$. En Jamaica, el rechazo extremo que sentían los libres de color hacia la esclavitud hacía que muchos, como indicara un plantador blanco, prefiriesen «morirse de hambre» antes que realizar cualquier labor manual en el campo. Este rechazo también se traducía en un desprecio hacia los esclavos, a quienes trataban severamente hasta el punto que algunos esclavos manifestaron tener preferencia por amos blancos ${ }^{52}$.

En el caso de los Coloreds, estos manifestaban además desprecio por los Negros Libres, negándose a enviar sus hijos a escuelas donde fuesen tratados igual que los hijos de estos, oponiéndose a que se concediesen privilegios a cualquier individuo de condición inferior a la suya, llegando a insultarlos de «neger» [sic] si tenían un pleito, y prefiriendo que sus hijas vivieran en concubinato con un blanco antes de casarse con un negro ${ }^{53}$. En Venezuela, las élites pardas se comportaban en forma parecida; no enviaban a educar sus hijos a la metrópoli, pero en 1805 solicitaron una escuela a la cual solamente podrían asistir niños de su condición. Por otro lado, condenaban cualquier individuo de su mismo nivel que retrocediera en el orden socio-racial, como

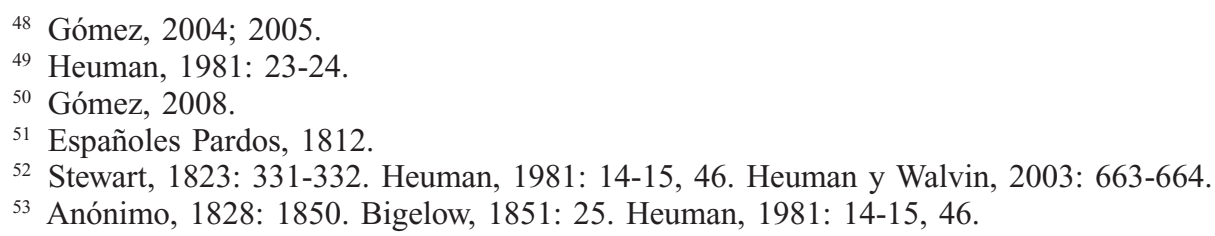


puede apreciarse claramente en la petición que hicieran los miembros de un batallón de pardos en 1774. En ella piden que se excluya de su cuerpo a un miembro arguyendo que era Zambo o «tente en el aire», con lo cual, desde su punto de vista, «...en lugar de adelantarse a ser blancos, han retrocedido, y se han acercado a la casta de los negros» ${ }^{54}$. También podría darse el caso contrario, es decir, que un pardo de la élite se negase a incorporarse a un cuerpo conformado por individuos de condición inferior. Esto se vio en Santiago de Chile en 1760, cuando un miliciano pardo se negó a ser incorporado como capitán a una compañía de Zambos «por ser requinterón» ${ }^{55}$.

\section{Alianza natural con los Blancos}

Paralelamente a los temores existentes sobre las posibles colaboraciones entre libres de color y esclavos, también existía la convicción en los Blancos de que los primeros constituían una suerte de «barrera contra los designios de los negros», para usar la expresión de un reverendo británico en Jamai$\mathrm{ca}^{56}$. Similares aseveraciones las encontramos en el Atlántico Francés en los reportes previos al cambio de actitud frente a los Gens de couleur, así como en la referida entrada de l'Encyplopédie ${ }^{57}$. En efecto, la experiencia había probado esta suerte de «alianza natural» en numerosas ocasiones. De hecho, las distintas milicias de color con frecuencia se encargaban de controlar las rebeliones de esclavos y de perseguir a los fugitivos. La lealtad de estos cuerpos fue puesta a prueba en forma dramática a fines del siglo XVIII: en 1791, tras el estallido de la gran revuelta de la Plaine du Nord en Saint-Domingue (en cuya represión participó un hermano de Raimond); y en 1795, durante la Guerra de Cimarrones en Jamaica. En el primer caso, pese a que recientemente se había sofocado en forma brutal una insurrección de mulatos, los libres de color no vacilaron en unir fuerzas con los Blancos para combatir los miles de esclavos sublevados. Esta alianza luego se formalizó, e incluso se extendió a los sectores más bajos de los libres de color, dando nacimiento a una frágil alianza, el llamado Concordato de septiembre 1791; mediante el cual los Blancos se comprometían a reconocer, e incluso a ampliar, los derechos que les había otorgado la asamblea legislativa metropolitana un año antes. En el caso de Jamaica, la fidelidad demostrada por los libres de color durante

\footnotetext{
${ }^{54}$ Cf. Rodulfo Cortés, 1978: 21.

55 Contreras, 2006: 107.

${ }^{56}$ Edwards, 1793: 26n.

57 Rogers, 2003: 87.
} 
la Guerra de Cimarrones de 1795, hizo que al año siguiente se les concediera una de sus principales aspiraciones: poder presentar evidencia contra los Blancos en juzgados en caso de agresión. Este privilegio estaba restringido a quienes hubieran sido bautizados en la iglesia anglicana y pudiesen presentar certificados de libertad, por lo que el alcance de la medida era muy limitado ${ }^{58}$.

Esta solidaridad con los Blancos era subrayada en ocasiones por los mismos libres de color, a la hora de hacer alguna declaración o solicitud como se viera anteriormente en las propuestas de los delegados en París de las elites cuarteronas franco-dominicanas. Mucho más tarde, en los años 1820, seguimos encontrando manifestaciones de solidaridad similares, como se puede apreciar en el caso de Cyrille Bissette. Este individuo de color quebrado martiniqués se convirtió en uno de los más activos críticos del sistema colonial francés, incluyendo de la esclavitud. No obstante, en un principio al menos, su postura se centró únicamente en la defensa de los individuos de su propia condición, en términos que recuerdan los argumentos usados por Raimond. En sus textos, critica la discriminación de la que seguían siendo objeto los libres de color en las provincias de ultramar francesas, lo cual no solamente contravenía sus derechos naturales establecidos en el Código Negro de 1685, sino que además, según él, iba en sentido opuesto al «...estado actual de la civilización». Bissette arguyó, por otro lado, que no podía haber sino dos tipos de hombres: libres y esclavos. También menospreció a los Blancos Criollos, tildándoles de cobardes por haber ofrecido en el pasado las islas a los ingleses, y alegando que sus ancestros eran piratas, vagabundos y reos fugados que constituían la «escoria de Francia» ${ }^{59}$.

Un panfleto atribuido a su persona titulado De la situation des gens de couleur libres aux Antilles Françaises que circulara en 1823, fue considerado como sedicioso, lo que condujo a Bissette y a cientos de franco-antillanos de color a largas penas de prisión y al destierro. A los condenados se les acusó de estar incentivando una revuelta de esclavos, lo que estos no solamente negaron, sino que además -como indicara claramente uno de ellos-aprovecharon para subrayar en su defensa el importante papel que tradicionalmente habían jugado los libres de color en tanto que fuerza contra las insurrecciones de esclavos. Prácticamente todos los textos evocan la rebelión que estallara en Le Corbet (Martinica) en 1822, en cuya represión participaron las milicias de color, incluyendo al mismo Bissette; para lo cual, como alegara su abogado en el proceso judicial en su contra, debió abandonar a su madre que agonizaba para cumplir con su deber ${ }^{60}$.

\footnotetext{
${ }^{58}$ Heuman, 1981: 24. Dubois, 2004: 120-121.

59 Cf. Mesnard, 2003: 259.

${ }^{60}$ Mesnard, 2003: 257.
} 
El llamado «Asunto Bissette» contribuyó a sensibilizar la opinión pública metropolitana, lo que unido al apoyo de los políticos liberales, facilitó la aprobación de un decreto que otorgaba a los libres de color completa ciudadanía en 1833. No obstante, debido al costoso impuesto electoral, no fue sino hasta 1845 que un hombre de color pudo finalmente ocupar un curul en el Consejo Colonial de la isla de Martinica. Las luchas contra el sistema colonial llevaron a Bissette y a otros individuos de su condición a abrazar la causa abolicionista en 1834, convirtiéndose él mismo en uno de los principales anti-esclavistas en el Atlántico Francés. Empero, la abolición de la esclavitud conseguida en 1848 en poco o nada contribuyó a acercar a los Gens de couleur de Martinica a los Negros. Al menos esto es lo que podría interpretarse del frente común que nuevamente hicieron con los Blancos, para reprimir las manifestaciones masivas de Negros que estallaron en la isla en $1870^{61}$.

\section{Las peticiones de los Coloreds jamaiquinos}

Al igual que en las Antillas francesas, los Coloreds en Jamaica retomaron en el primer tercio del siglo XIX sus reclamos en pos de recuperar los derechos inmemoriales que le habían legado sus ancestros blancos. Más concretamente, buscaron poner fin a las restricciones hereditarias y a las que impedían todavía a muchos poder testimoniar en las cortes contra los Blancos, así como también a la discriminación en las cuotas de trabajadores de color en las plantaciones (save deficiency). En 1812, dos peticiones firmadas por 2400 Coloreds fueron elevadas ante la Asamblea Legislativa, cuyos miembros, aunque inicialmente resolvieron que los individuos de esa condición no tenían derecho a reclamar, por temor o bajo presión del gobernador, debieron satisfacer sus demandas. La ley resultante quedó en gran medida como letra muerta, por lo que los peticionarios volvieron a la carga en 1816 y de nuevo en 1823, esta vez exigiendo directamente tener los mismos privilegios que los Blancos. Es importante destacar que en todo momento aceptaban el sistema esclavista, y que incluso, como pasara en su campaña de 1823, no incluían a los Negros Libres, dejando a la asamblea la potestad de «...extender a la Población Negra Libre, o no, según lo considerase necesario, los privilegios solicitados por la Gente de Color». Esto hizo que un grupo de Negros Libres hiciera por su cuenta una petición similar ese mismo año, y criticó sus egoístas pretensiones estamentales. La asamblea no hizo discrepancias, y consideró las dos peticiones como una sola ${ }^{62}$.

\footnotetext{
${ }^{61}$ Ibidem: 259-260. Bruneteaux, 2013b: 40.

${ }^{62}$ Heuman, 1981: 28, 46.
} 
En esa misma época, los Coloreds organizaron un comité para lograr que finalmente se eliminaran las restricciones restantes, como las que impedían que fuesen jurados en cortes y que pudiesen ocupar cargos públicos. Sus delegados también hicieron lobby en el Parlamento, e incluso se acercaron a los abolicionistas metropolitanos para que incluyeran la causa de los Coloreds en su agenda. Este acercamiento avivó los temores en los Blancos de una rebelión conjunta de libres de color y esclavos, tanto más cuanto dos de quienes estaban preparando la petición, Louis Céleste Lecesne y John Escoffery, eran de origen haitiano. Esto hizo que ambos individuos fuesen inmediatamente deportados a Haití; de aquí pasaron a Inglaterra, donde los abolicionistas usaron la injusticia cometida en su contra como argumento para criticar los prejuicios de los Blancos hacia la «raza africana». En 1830, ambos hombres fueron absueltos y retornaron a Jamaica siendo indemnizados por perjuicios materiales ${ }^{63}$.

En forma similar a como pasara con el «Asunto Bissette», la injusticia cometida sobre estos dos libres de color jamaiquinos aumentó la atención de los políticos metropolitanos sobre su causa. Incluso se permitió al intelectual de color, Richad Hill, intervenir directamente ante la Cámara de los Comunes. Eventualmente, en 1829, el gobierno metropolitano ordenó que se considerara como súbditos británicos a los individuos libres de color que habitaban en las Colonias de la Corona (Crown Colonies) de Santa Lucía y Trinidad. Por otro lado, ante el recrudecimiento de las actividades de los abolicionistas metropolitanos, muchos Blancos jamaiquinos comenzaron a apoyar las demandas de los libres de color, buscando hacer un frente común para mantener la esclavitud. Esta situación hizo que en febrero de 1830, la Asamblea Legislativa aprobara dos mociones que otorgaban privilegios igualitarios a todos los libres de color, pero con pesadas exigencias censitarias que buscaban evitar que estos pudiesen eventualmente dominar la asamblea ${ }^{64}$.

Los Coloreds consideraron estas concesiones como un insulto, y retomaron sus actividades reivindicadoras a ambos lados del Atlántico, buscando esta vez obtener total igualdad con los Blancos. Para ese momento, las presiones de los abolicionistas en la metrópoli hicieron más urgente que nunca la necesidad de contar con el apoyo de los libres de color, para contrarrestar sus esfuerzos. En aras de propiciar un acercamiento, en diciembre de aquel año la asamblea aprobó una moción que les otorgaba finalmente los mismos privilegios que gozaban los Blancos. Empero, como bien indica Gad Heuman, la alianza esperada por estos no sería posible, debido a las muchas trabas y dilaciones

63 Ibidem: 27-39.

${ }^{64}$ Hall, 1972: 203-205. Heuman, 1981: 41-50. 
que los asambleístas habían puesto en los últimos años. Esta situación más bien fomentó algo hasta entonces impensable: la unión política entre Coloreds y Negros Libres. En octubre de 1831, fueron electos por primera vez dos individuos de color (ambos de color quebrado) como representantes en la Asamblea Legislativa de Jamaica ${ }^{65}$.

\section{A MANERA DE CONCLUSIÓN}

Como se ha podido apreciar, la aceptación y práctica de los valores raciales tradicionales de los Blancos Criollos por parte de las elites de color quebrado (lo cual se reflejó sobre todo en sus estrategias familiares para defender su estatus «blanqueado» o acercarse al de blanco), les llevó a despreciar a otros sectores de color que se encontraban por debajo en la escala socio-racial. En un sentido inverso, pese al desprecio colectivo que sentían los Blancos hacia ellos (y, en general, hacia todos los afro-descendientes de color), dichas élites siguieron apoyándoles en tiempos de revueltas de esclavos y de protestas de negros emancipados, incluso tras las aboliciones de la esclavitud. Por otro lado, sus intereses clasistas y estamentales, les hicieron tomar rutas de accionar político que la mayor parte del tiempo estuvieron alejadas de la causa abolicionista, y también de los ideales socio-liberales cuando estos beneficiaban a los sectores inferiores de libres de color.

En las Antillas Menores francesas, tras la abolición de la esclavitud en 1848 las burguesías sang-mêlées y las élites blanco-criollas o Békés monopolizaron el poder político, asegurando la continuidad colonial francesa ${ }^{66}$. Hacia fines del siglo XIX, el célebre abolicionista Victor Schœlcher se lamentaba en su diario personal viendo cómo «esos mulatos degenerados hagan [hacían] alianza con los Blancos con la esperanza de acercarse a ellos» ${ }^{67}$. En Haití, tras la independencia, luego de una breve separación del territorio entre un reino negro al Norte y una república mulata al Sur, en 1822, la totalidad del territorio de la isla fue unido por las siguientes dos décadas bajo la presidencia del general mulato, Jean-Pierre Boyer. Durante ese tiempo, los mulatos controlaron el poder político y económico en la isla, llegando incluso a endurecer la política rural para mantener a los ex-esclavos trabajando en las plantaciones ${ }^{68}$. En Jamaica, tras el acercamiento con los Negros en la víspera de la

\footnotetext{
${ }^{65}$ Hall, 1972: 203. Heuman, 1981: 49-50.

${ }^{66}$ Bruneteaux, 2013b: 91-94.

67 Ibidem: 91.

${ }^{68}$ Laviña, 2014: 50-51.
} 
abolición de la esclavitud, hubo políticos de color quebrado que se interesaron sinceramente por la precaria situación de los ex-esclavos. Tal fue el caso de George Willaim Gordon, quien fue acusado de instigación a la rebelión y ejecutado tras la insurrección masiva de trabajadores negros en Morant Bay de 1865. Tras este hecho, todos los afro-descendientes jamaiquinos perdieron representatividad política, ya que la isla pasó seguidamente a ser una Colonia de la Corona ${ }^{69}$. En Venezuela, la situación fue muy distinta, pues la guerra de independencia acabó de facto con el orden socio-racial colonial, y con él también desaparecieron en gran medida las élites, tanto las blanco-criollas como las de pardos. No obstante, las élites (blancas o pardas blanqueadas) que surgieron o renacieron tras el conflicto marginalizaron a las minorías negras en términos de clase y de esclavitud, la cual se mantuvo hasta $1854^{70}$.

En este mismo orden de ideas, la identidad que desarrollaron las élites de color quebrado como sector distintivo cercano a los Blancos, así como las posturas clasistas y racistas que manifestaron tener a fines de la modernidad, afectaron negativamente y en forma duradera las relaciones entre sus descendientes y los Negros en el período post-esclavista. Este hecho marcó profundamente las ideas y sensibilidades de muchos de los líderes del nacionalismo pan-africano, como en los casos del jamaiquino Marcus Garvey y del franco-antillano Aimé Césaire ${ }^{71}$. Por otro lado, también nutrió los imaginarios de formas más contemporáneas de endo-racismo (por ejemplo, las asociadas a la tonalidad de la piel) y de resentimiento racial hacia los sectores de color quebrado. En Haití, las diferencias tradicionales entre mulatos y Negros marcaron la historia política de este país en los siglos XIX y XX. Este hecho ha dificultado además la formación de una identidad nacional, siendo la mejor evidencia de ello la formación de dos historicismos paralelos de corte racial que David Nicholls denomina como «leyenda mulata»y «leyenda negra» ${ }^{72}$.

${ }^{69}$ Heuman, 1981: 183-193.

70 Wright, 1990: 29-31, 57-58.

${ }^{71}$ Esas posturas fueron, en efecto, vistas por intelectuales y literatos negros, si no como una suerte de «traición» a su lado africano (en un sentido que recuerda las dolencias presentadas por el supuesto esclavo de Martinica en 1789), al menos sí como muestra de su «dificultad»para superar su ambigua dicotomía socio-racial. Por esta razón, a principios del siglo XX, durante el llamado Renacimiento de Harlem, el activista jamaiquino, Marcus Garvey, excluyó de la «raza negra» a los Browns a quienes además tildaba de «monstruos» y acusaba de explotar también a los Negros. A mediados de siglo, la aceptación del de la dependencia metropolitana por parte de la burguesía y políticos de color quebrado en las Antillas Francesas tuvo que ver en gran medida con el desarrollo de la noción incluyente de Négritude propuesta por Aimé Césaire. Walker, 1991: 51. Arnold, 1998. Luilyan, 2001: 52ss. Niort, 2002. Fairclough, 2002: 114. Badiane, 2009: 39. Bruneteaux, 2013a.

72 Nicholls, 1996: 8-11. Quinn y Sutton, 2013. 
Finalmente, en Venezuela, como pasara con los indios en otros países de América Latina, el negro fue en gran medida «invisibilizado» ante la aplicación de políticas blanqueadoras y el desarrollo de un imaginario nacional dominado por nociones mestizas euro-africanas como la de «café con leche»; aunque, como bien indicara Winthrop Wright, con más «leche» que «café»» ${ }^{73}$.

Esta apertura hacia la contemporaneidad, forzosamente incompleta, muestra hasta qué punto los valores socio-raciales de las sociedades tripartitas gran caribeñas sobrevivieron y se adaptaron a las nuevas realidades post-esclavistas. En efecto, la «zona gris» en la que las élites de color quebrado gozaron de privilegios limitados, aseguró la continuidad en el tiempo de las relaciones de poder coloniales y del mismo colonialismo en los territorios insulares estudiados. No obstante, la misma zona también permitió la apertura de una gran brecha por la que dichas elites pudieron reclamar sus derechos desde fines del siglo XVIII. Curiosamente, al hacerlo abrieron también la «caja de pandora» que inició - $\mathrm{O}$, más bien, desencadenó- las revoluciones «desde abajo» en el espacio franco-caribeño. Este ejemplo animó a otros individuos de color quebrado a hacer peticiones o a participar activamente en procesos políticos revolucionarios, como se viera respectivamente en Jamaica y el Circum-Caribe hispano. Todo ello contribuiría enormemente al surgimiento regímenes más igualitarios (como se viera sobre todo en Haití y la Tierra Firme hispana), y al eventual derrumbamiento del orden esclavista. A fin de cuentas, era en la esclavitud donde se encontraba el origen de la principal mácula que permitía su discriminación.

\section{BiBLIOGRAFÍA}

Anónimo, Marly, or, A planter's life in Jamaica, Glasgow, R. Griffin, 1828.

Arnold, Albert James, Modernism and Negritude: The Poetry and Poetics of Aimé Césaire, Cambridge, Harvard University Press, 1998.

D'Auberteuil, Michel René Hilliard, Considérations sur l'état présent de la colonie francaise de Saint-Domingue: ouvrage politique et législatif : présenté au Ministre de la Marine, vol. 2, París, Grangé, 1777.

Badiane, Mamadou, The Changing Face of Afro-Caribbean Cultural Identity: Negrismo and Negritude, Plymouth, Lexington Books, 2009.

\footnotetext{
73 Wright, 1990: 131.
} 
Bénot, Yves, La révolution française et la fin des colonies: Essai, París, La Découverte, 1988.

Bigelow, John, Jamaica in 1850, or, The effects of sixteen years of freedom on a slave colony, New York, G. P. Putnam, 1851.

Bruneteaux, Patrick, Le colonialisme oublié: de la zone grise plantationnaire aux élites mulâtres à la Martinique, Bellecombe-en-Bauges, Croquant, 2013a.

Bruneteaux, Patrick, "De la stratification socio-raciale à la zone grise au travers de quelques œuvres littéraires martiniquaises", Asylon(s), 11 (2013b), http://www. reseau-terra.eu/article1292.html (Fecha de Consulta: 13/02/2015).

Burnard, Trevor, “'Rioting in goatish embraces': Marriage and improvement in early British Jamaica", The History of the Family, 11/4 (2006): 185-197.

Cohen, David W. y Greene, Jack P. Greene (eds.), Neither slave nor free; the freedman of African descent in the slave societies of the New World, Baltimore, Johns Hopkins University Press, 1972.

Contreras Cruces, Hugo, "Las milicias de pardos y morenos libres de Santiago de Chile en el siglo XVIII, 1760-1800”, Cuadernos de Historia, 25 (Santiago de Chile, 2006): 93-117.

Contreras Cruces, Hugo, “Artesanos mulatos y soldados beneméritos: El Batallón de Infantes de la Patria en la Guerra de Independencia de Chile, 1795-1820", Historia, 44/1 (Santiago de Chile, 2011): 51-89.

Cook, Mercer, “Julien Raimond”, Journal of Negro History, XXVI/2 (1941): 139-170.

Cousseau, Vincent, "La famille invisible. Illégitimité des naissances et construction des liens familiaux en Martinique (XVIIe siècle - début du XIXe siècle)", Annales de démographie historique, 122/2 (París, 2012): 41-67.

Davis, David Brion, The Problem of Slavery in Western Culture, New York, Oxford University Press, 1988.

Dubois, Laurent, Avengers of the New World: The Story of the Haitian Revolution, Cambridge, Belknap Press of Harvard University Press, 2004.

Edwards, Bryan, The History, Civil and Commercial, of the British Colonies in the West Indies, vol. 2, London, Printed for J. Stockdale, 1793.

Edwards, Bryan, The history, civil and commercial, of the British colonies in the West Indies, vol. 2, London, Stockdale, 1794.

Elisabeth, Léo, La société martiniquaise aux XVIIe et XVIIIe siècles: 1664-1789, París, Fort-de-France, Karthala, Société d'histoire de la Martinique, 2003.

Españoles Pardos, Colección de los discursos que pronunciaron los señores diputados de América contra el artículo 22 del proyecto de constitución. Ilustrados 
con algunas notas interesantes por los españoles pardos de esta capital, Lima, Imprenta de los Huérfanos, 1812.

Fairclough, Adam, Better Day Coming: Blacks and Equality, 1890-2000, New York, Penguin, 2002.

Garrigus, John D., "Redrawing the Colour Line: Gender and the Social Construction of Race in Pre-Revolutionary Haiti", Journal of Caribbean History, 30/1 y 2 (1996): 28-50.

Garrigus, John D., Before Haiti: Race and Citizenship in French Saint-Domingue, New York, Palgrave Macmillan, 2006.

Geggus, David P., "The Haitian Revolution”, Hilary Beckles \& Verene Shepherd (ed.), Caribbean slave society and economy: a student reader, New York, New Press, 1991.

Gerber, Matthew, "Bastardy, Race, and Law in the Eighteenth-Century French Atlantic: The Evidence of Litigation", French Historical Studies, 36/4 (2013): 571-600.

Gómez, Alejandro E., “¿Ciudadanos de color? El problema de la ciudadanía de los esclavos y Gente de Color durante las revoluciones franco-antillanas, 1788-1804", Anuario de Estudios Bolivarianos, XI/5 (Caracas, 2005): 117-158.

Gómez, Alejandro E, "La Revolución de Caracas desde abajo. Impensando la primera independencia de Venezuela desde la perspectiva de los Libres de Color, y de las pugnas político-bélicas que se dieran en torno a su acceso a la ciudadanía, 17931815", Nuevo Mundo-Mundos Nuevos, 8 (París, 2008), http://nuevomundo.revues. org/32982 (Fecha de Consulta: 13/02/2015).

Gómez, Alejandro E., Fidelidad bajo el viento. Revolución y contrarrevolución en las Antillas Francesas (1790-1795), México, Siglo XXI, 2004.

Grégoire, Henri, De la noblesse de la peau, ou, Du préjugé des blancs contre la couleur des africains et celle de leurs descendants noirs et sang-mêlés, París, Jérôme Millon, c1996 (1826).

Guaman Poma de Ayala, Felipe, El primer nueva corónica y buen gobierno, 1615.

Hall, Douglas, “Jamaica”, David William Cohen \& Jack P. Greene (ed.), Neither slave nor free; the freedman of African descent in the slave societies of the New World, Baltimore, Johns Hopkins University Press, 1972.

Helg, Aline, "Race and Black Mobilization in Colonial and Early Independent Cuba: A Comparative Perspective", Ethnohistory, XCIV/1 (1997): 53-74.

Helg, Aline, Liberty \& Equality in Caribbean Colombia, 1770-1835, Chapel Hill, University of North Carolina Press, 2004.

Hernández Jaimes, Jesús, “Cuando los mulatos quisieron mandar”, José Gilberto Garza y Tomás Bustamante (eds.), Los sentimientos de la nación. Entre la espa- 
da espiritual y militar y los orígenes del Estado de Guerrero, México, Editorial Laguna, 2001.

Heuman, Gad J., Between Black and White: Race, Politics, and the Free Coloreds in Jamaica, 1792-1865, Westport, Greenwood Press, 1981.

Heuman, Gad J. y Walvin, James (eds.), The slavery reader, London, New York, Routledge, 2003.

Humboldt, Alexander von, Essai politique sur le royaume de la Nouvelle-Espagne, vol. 2, París, Chez F. Schoell, 1811.

Humboldt, Alexandre de, Essai Politique sur le Royaume de la Nouvelle-Espagne, vol. 1, París, Rénouard, 1825.

King, Stewart R., Blue Coat Or Powdered Wig: Free People of Color in Pre-revolutionary Saint Domingue, Athens, University of Georgia Press, 2011.

Langue, Frédérique, "La pardocratie ou l'itineraire d'une "classe dangereuse" dans le Venezuela des XVIIIe et XIXe siècles”, Caravelle, 67 (Toulouse, 1997): 57-72.

Lasso, Marixa, Myths of Harmony: Race and Republicanism during the Age of Revolution, Colombia, 1795-1831, Pittsburgh, University of Pittsburgh Press, 2007.

Laviña, Javier, “Trabajo y postemancipación en Haití”, Boletín Americanista, LXIV/68 (Barcelona, 2014): 37-54.

Long, Edward, The History of Jamaica; Or, general survey of the antient and modern state of that island; with reflections on its situation, settlements, inhabitants, vol. 3-II, London, T. Lowndes, 1774.

Luilyan, Kesteloot, Histoire de la littérature négro-africaine, París, Karthala, 2001.

McKinley, P. Michael, Caracas antes de la independencia, Caracas, Monte Avila editores latinoamericana, 1993.

Mesnard, Éric, "Resistance Movements in the French Colonies: The Bissette Affair (1823-1827)", Marcel Dorigny (ed.), The Abolitions of Slavery: From Léger Félcité Sonthonax to Victor Schoelcher, 1793, 1794, 1848, París, UNESCO, Berghahn Books, 2003: 255-260.

Miranda, Francisco de, Archivo del General Miranda, vol. XXI, Caracas, Tipografía Americana, 1938.

Nicholls, David, From Dessalines to Duvalier: Race, Colour, and National Independence in Haiti, New Brunswick, Rutgers University Press, 1996.

Niort, Jean-François, "La condition des libres de couleur aux îles du vent (XVIIeXIXe siècles) : ressources et limites d'un système ségrégationniste", Bulletin de la Société d'histoire de la Guadeloupe, 131 (Basse-Terre, 2002). 
Pellicer, Luis Felipe, La vivencia del honor en la provincia de Venezuela, 1774-1809: estudio de casos, Caracas, Fundación Polar, 1996.

Pellicer, Luis Felipe, Entre el honor y la pasión, Caracas, Universidad Central de Venezuela, 2005.

Pouliquen, Monique, Doléances des peuples coloniaux à l'Assemblée nationale constituante, 1789-1790, París, Archives nationales, 1989.

Quinn, Kate y Sutton, Paul, Politics and Power in Haiti, New York, Palgrave Macmillan, 2013.

Raimond, Julien, Observations sur l'origine et les progrès du préjugé des colons blancs contre les hommes de couleur, sur les inconvénients de le perpétuer, la nécessité, la facilité de le détruire, sur le projet de comité national, etc., París, Bailly, 1791.

Regent, Frédéric, "Structures familiales et stratégies matrimoniales des libres de couleur en Guadeloupe au XVIIIe siècle", Annales de démographie historique, 122/2 (París, 2012): 69-98.

Rodulfo Cortés, Santos, El régimen de "las Gracias al Sacar" en Venezuela durante el Período Hispánico, Caracas, Academia Nacional de la Historia, 1978.

Rogers, Dominique, "De l'origine du préjugé de couleur en Haïti”, Outre-mers, 90/340 (París, 2003): 83-101.

Rogers, Dominique, "On the Road to Citizenship: The Complex Route to Integration of the Free People of Color in the Two Capitals of Saint-Domingue", David Patrick Geggus y Norman Fiering, (eds.), The World of the Haitian Revolution, Bloomington, Indiana University Press, 2009.

Santacilia, Jorge Juan y Ulloa, Antonio de, Relacion Historica Del Viage A La America Meridional Hecho De Orden De S. Mag. Para Medir Algunos Grados De Meridiano Terrestre, y venir por ellos en conocimiento de la verdadera Figura, y Magnitud de la Tierra, con otras varias Observaciones Astronomicas, y Phisicas, Madrid, Marin, 1748.

Sio, Arnold A., "Race, Colour, and Miscegenation: The Free Coloured of Jamaica and Barbados", Caribbean Studies, 16/1 (San Juan, 1976): 5-21.

Solano, Sergio Paolo, "Repensando la configuración socio-racial del Nuevo Reino de Granada, siglo XVIII: pardos, mulatos, cuarterones y quinterones”, Aguaita, 25 (Cartagena de Indias, 2013): 39-59.

Stewart, J., A view of the past and present state of the island of Jamaica with remarks on the moral and physical condition of the slaves, and on the abolition of slavery in the colonies, Edinburgh, Oliver \& Boyd, 1823.

Trollope, Anthony, The West Indies and the Spanish Main., New York, Harper \& Brothers, 1860. 
Twinam, Ann, Purchasing Whiteness: Pardos, Mulatos and the Quest for Social Mobility in the Spanish Indies, Stanford, Stanford University Press, 2015.

Walker, Clarence Earl, Deromanticizing Black History: Critical Essays and Reappraisals, Knoxville, University of Tennessee Press, 1991.

Wimpffen, Alexandre-Stanislas, Haïti au XVIIIe siècle: richesse et esclavage dans une colonie française, París, Karthala, 1993.

Wright, Winthrop R., Café con Leche: Race, Class, and National Image in Venezuela, Austin, University of Texas Press, 1990.

Zuñiga, Jean-Paul, “La voix du sang. Du métis à l'idée de métissage en Amérique espagnole", Annales. Histoire, Sciences Sociales, 54/2 (París, 1999): 425-452.

La Révolution française et l'abolition de l'esclavage, vol. 11, París, EDHIS, 1968.

Fecha de recepción: 4 de noviembre de 2014.

Fecha de aceptación: 11 de febrero de 2015.

\section{ONLY A PART OF BLACK \\ Socio-racial values and political agency of "mixed-blood" elites in Jamaica, Venezuela, and the French Antilles, $18^{\text {th }}$ and $19^{\text {th }}$ centuries.}

This essay compares the socio-racial prejudices and egalitarian aspirations of "mixedblood" elites of Jamaica, Venezuela, and the French Antilles. The aim is to show how these factors affected the political activities of the members of that sector, especially during the revolutionary period and the abolitionist era. We argue that their activities had contradictory consequences fostering both the perpetuation and the downfall of discriminatory regimes established during the colonial era.

KEY WORDS: Caribbean; race; revolutions; equality; citizenship; mulattos. 